Fanum

Sociológico
Forum Sociológico

Série II

$25 \mid 2014$

Número 25

\title{
Aspectos de uma sociologia do imaginário na pós- modernidade: a razão sensível
}

\section{Eduardo Portanova Barros}

\section{(2) OpenEdition \\ Journals}

\section{Edição electrónica}

URL: https://journals.openedition.org/sociologico/920

DOI: 10.4000/sociologico.920

ISSN: 2182-7427

\section{Editora}

CICS.NOVA - Centro Interdisciplinar de Ciências Sociais da Universidade Nova de Lisboa

\section{Edição impressa}

Paginação: 81-86

ISSN: 0872-8380

\section{Refêrencia eletrónica}

Eduardo Portanova Barros, «Aspectos de uma sociologia do imaginário na pós-modernidade: a razão sensível», Forum Sociológico [Online], 25 | 2014, posto online no dia 10 novembro 2014, consultado o 30 março 2022. URL: http://journals.openedition.org/sociologico/920 ; DOI: https://doi.org/10.4000/ sociologico.920

Este documento foi criado de forma automática no dia 30 março 2022.

(c) CICS.NOVA 


\title{
Aspectos de uma sociologia do imaginário na pós-modernidade: a razão sensível
}

\author{
Eduardo Portanova Barros
}

1 Bastante utilizada, e de qualquer jeito, principalmente pela mídia, a palavra imaginário mereceu - e ainda merece - a atenção de diversos pensadores. No Brasil, algumas escolas estudam o que poderia ser definido como, seguindo a linhagem de Gaston Bachelard, Gilbert Durand e Michel Maffesoli, o equilíbrio no ser humano entre as coerções objetivas e as pulsões subjetivas. O que isso quer dizer? Ora, é que vivemos um permanente paradoxo entre aspectos objetivos e subjetivos da existência. $O$ corpo, que é materialidade, pensa (subjetivamente). A tecnologia, portanto, esse concreto mais extremo, é produto do nosso imaginário. Assim, pode-se afirmar que tanto o imaginário é real quanto o real é imaginário. E é a partir desse pressuposto que este trabalho se configura, fazendo um levantamento de diversos autores que estimulam (uns mais, outros menos) o debate em torno desse assunto na pós-modernidade.

2 A longa tradição cientificista tem dificuldade em aceitar pesquisas que não sejam quantificáveis. Por isso, o imaginário, que não se presta a isso, pois não pertence ao reino dos números e das medidas, é um tema controvertido - para não dizer atacado no terreno acadêmico. "Na fenomenologia do imaginário, a imaginação é colocada em primeiro lugar como princípio de excitação direta do devir psíquico", ensina Bachelard (1988: 8). A reversibilidade do imaginário no homem é constante. Ou seja, o homem produz o imaginário que o produz. $O$ imaginário na concepção lacaniana era tripartido entre o próprio imaginário, o simbólico e o real, fragmentando a noção relacional do termo, segundo Maffesoli. A leitura de Bachelard era outra, a do deslizamento na pessoa entre suas intimações objetivas e sua subjetividade. Diferentemente de ideologia, que tem um cunho racionalizante, imaginário é, antes, uma força ambivalente, que junta os aspectos emocionais e racionais próprios de nossa condição 
antropológica.

Não se trata de afirmar que o imaginário se prende pouco ou muito com a racionalização, e sim que a racionalização é um traço humano da mesma forma que as pulsões subjetivas (sem querer entrar no mérito psicanalítico)

3 Conforme Durand, o imaginário estava bloqueado pelo positivismo, o que, mais tarde, graças ao trabalho de Sigmund Freud, acabou mudando, pois ele começa a dar importância para conteúdos do inconsciente pela via psicanalítica. Depois veio Jung e a psicologia profunda com a noção de arquétipo. Durand assume sua escolha pelo imaginário como um caminho de teor científico, mas não cartesiano (que postulava a evidência como método universal). Isto é, não conforme as leis de uma ciência dura. De formação antropológica, Durand vê o simbolismo ligado à hominização, quando os antropoides assumem, num certo momento, a postura ereta. A partir do corpo, passa a acontecer uma série de descobertas e de escolhas do ponto de vista instrumental. Esse caminho, o que Durand prefere chamar de "trajeto antropológico", é o foco de sua pesquisa. Para Durand, a imagem é fornecida pela cultura e pela estética, cujo estudo é desenvolvido pelo Centro de Pesquisa sobre o Imaginário, na segunda metade dos anos 1960. São organizados diversos encontros (seminários, colóquios, jornadas) para a discussão em torno do imaginário social.

Do ponto de vista acadêmico, o interesse se volta para análises temáticas e uma metodologia do imaginário. $O$ intenso intercâmbio entre o Centre de Recherche sur l'Imaginaire (CRI), fundado em dezembro de 1966, e outros laboratórios, além de revistas ao redor da Europa, fomentam as discussões em torno do imaginário. Os assuntos variam desde os sistemas simbólicos até a antropologia urbana, passando, também, por temáticas como a do mito, da criatividade, da forma, do espaço e da transgressão, apenas para citar algumas delas. Durand procura pensar em termos de polaridade. Logo, fatores mecânicos não se separam da imagem simbólica. 0 simbolismo em Durand é não-arbitrário e não-convencional. É quando o signo perde sua arbitrariedade e remete às abstrações, sobretudo espirituais e morais.

Um detalhe interessante na história do CRI é que Durand forma o Departamento de Estética e de Poética. Trata-se de uma religação entre a imagem e a expressão decorrente dela. 0 termo imagem, quando ligado ao simbólico, não se refere àquilo que se apresenta visualmente para nós. A imagem de um pássaro em pleno voo é a de liberdade, e não a mecânica do voo (Bachelard), isto é: asas que se abrem e que se fecham (mesmo que seja dessa mecânica que se forma a imagem abstrata). Outro exemplo é quando Bachelard se refere ao verão como a estação do ramalhete (um ramalhete eterno, que não murcha).

6 Bachelard pergunta: "Como pode o homem, apesar da vida, tornar-se poeta?" (1988: 10). Trata-se de uma questão das mais pertinentes. Aqui, o autor de A poética do devaneio explicita a natureza humana de aprisionamento a um corpo físico que sonha. $\mathrm{O}$ que Bachelard apresenta pode ser uma síntese da ideia de imaginário: ou seja, o aprisionamento e o sonho, as condicionantes históricas e os afetos. Sociologicamente falando, Maffesoli se vale desse paradoxo em A transfiguração do político e 0 mistério da conjunção, para enfatizar, respectivamente, que o estado-nação morreu - se é que no Brasil existiu algum dia - e que uma ambiência emocional toma lugar da argumentação. O que mais funciona, para ele, são as trocas, as possibilidades de contato. O caos é melhor do que o excesso de organização. A repressão pode gerar violência, algo que, na psicanálise, poderia ser o equivalente ao retorno do recalcado. Por falar nisso, Maffesoli 
não se interessa em julgar psicanaliticamente a sociedade, mas antes em compreendêla. Nisso, Maffesoli se inspira em Nietzsche ao criticar (para pôr em crise) "os melhoradores do mundo".

7 Jean-François Lyotard alavancou a discussão sobre o pós-moderno. Segundo ele, o problema é de natureza epistemológica, isto é: o que define o saber? O autor de $A$ condição pós-moderna observa diversas maneiras de se ver o social. A partir desse pressuposto, ele abre a discussão para situações que colidem com o saber oficial estruturado na dialética tese-antítese-síntese. Os metarrelatos já não significam muita coisa. Há, na pós-modernidade, uma desconfiança em relação aos instrumentos do saber. Aliás, como afirmar que um saber é verdadeiro? Outro autor, Paul Feyerabend (Contra o método), já mostra como diversas descobertas científicas podem ter sido fruto do acaso. Com isso, o epistemólogo austríaco critica o saber tradicional assentado no reducionismo. O paradoxo suscitado pela reflexão de Lyotard, portanto, é o de que tudo é passível de análise, mas nem tudo estaria de acordo com determinada ética. A ética social.

8 A crítica à ética mediática é a base do pensamento do ensaísta francês Jean Baudrillard. Estritamente falando, Baudrillard está longe de ser pós-moderno. Porém, sem tomar um rumo classificatório, a modernidade do autor de Tela total e Power inferno denuncia a ilusão mediática. Baudrillard utiliza a ironia para criticar uma sociedade massificada, revelando paradoxos e contradições sociais. Com base no conceito de simulacro, para Baudrillard tudo é reapropriação. Tudo é signo, e nós, humanos, não conseguimos escapar desse círculo vicioso. Se tudo é mostrado, não há mais nada para ser visto. Baudrillard opina que nos tornamos seres individualizados, e que isso não tem relação nenhuma com liberdade pessoal, mas sim com promiscuidade. 0 mundo é uma espécie de big brother televisivo.

9 Para sermos mais precisos, Baudrillard afirma que a "era da simulação inicia-se com uma liquidação de todos os referenciais" (1991: 9). Para ele, é possível separar o verdadeiro do falso e o real do imaginário. É isso que a simulação, segundo termos do próprio autor, "põe em causa". o principal termo que Baudrillard utiliza para justificar sua tese é o de hiper-real, como a "geração simulada das diferenças" (1991: 9). A simulação, portanto, nega o valor do signo e a sua referência. A ideia de signo foi evidenciada nos três cursos de linguística que Ferdinand de Saussure (1857-1913) ministrou entre 1906 e 1911 na Universidade de Genebra. Segundo ele, a língua é como que uma instituição social, isto é, uma organização desses signos para que, a partir daí, se possa refletir ou expressar algum tipo de ideia. É, na verdade, uma codificação da linguagem.

10 Toda a representação, que acredita numa falsa representação do que é simulado, acaba sendo um simulacro. Em outras palavras, perdeu-se a referência do signo porque ele próprio é um simulacro. Como crer na representação se a própria representação já não é representável? De fato, Baudrillard não desmascara o real porque nada mais do real existe - agora um hiper-real - para ser desmascarado. Mas, no grande plano, "descobrir" como se dá a representação não deixa de ser uma forma de desmascará-la, sim.

11 Baudrillard, Maffesoli e Morin foram os três principais teóricos franceses de uma sociologia da suspeita. Ou seja, a temática social não se esgota nela mesma, porque vai se contradizer o tempo todo e de modo complexo (Morin), ou trágico (Maffesoli). Não que as ideias de Baudrillard não sejam nem complexas ou trágicas, mas é Morin o 
patriarca da teoria segundo a qual somos homo, ao mesmo tempo, sapiens, demens, ludens, mitologicus e poeticus. E Maffesoli, aproveitando a deixa, acrescenta: eroticus (livro lançado no final de 2012). Essas dimensões do humano estão interligadas, e é precisamente esse aspecto que torna o pensamento complexo de Morin tão difícil de ser assimilado por quem pensa sob a lente da modernidade, a que vê tudo de forma fragmentada. Se nos dedicarmos a refletir demoradamente sobre a complexidade de Morin, veremos que ela não é tão simples como se imagina. Por exemplo: como entender que o universo é imperfeito, mas que essa imperfeição de que é feito também é a condição de sua existência? Com isso, Morin desmonta o saber prometeico, de avançar para corrigir, de crença no progresso, o que não deixa de ser a mesma crítica que faz Maffesoli à lógica do "dever-ser".

12 Detenhamo-nos um pouco mais no trabalho de Morin. Ao escrever, no final dos anos 50, sobre cinema, Morin destacou a relação entre o cinema e o (homem) imaginário. Ele próprio fez um filme: Cronique d'un été, de 1962, em co-autoria com o etnólogo Jean Rouch, no auge da nouvelle vague francesa. Morin despertou outros teóricos para o fato de que existe uma aura, antes sentida do que conscientizada, em toda ação humana. Esse aspecto fluido, que não pode ser descrito pela linguagem, mas nem por isso negligenciável, pode ser o imaginário. Vive-se, no caso do cinema, uma projeçãoidentificação com aquilo que é visto na tela. Para Morin, isso é tão significativo que resolveu escrever mais tarde, em 1972, outro livro sobre cinema, dessa vez sublinhando o aspecto mitológico das estrelas (As estrelas - mito e sedução no cinema). A tríade humano-biológico-cultural é inseparável no ser humano, diz Morin, pois ela carregaria nossos afetos, nossas pulsões e nossa racionalidade. Trata-se de um todo cujas partes até poderiam ser distintas, mas nunca isoladas entre si.

13 Morin fez questão de organizar seu pensamento metodologicamente. Os seis livros dessa fase, que se estendeu por vários anos e que foi concluída depois da virada do milênio com a publicação de 0 método 6 - ética, apresentam como que uma unidade múltipla (unitas multiplex) da sua tese. A ideia central do último trabalho na linha das metodologias é a de que a ética não pode escapar dos problemas da complexidade, e o conhecimento complexo se tornou vital na sociedade contemporânea. É preciso praticar a complexidade, e essa prática começa no indivíduo (o que, para Maffesoli, poderia ser mais bem designado pela palavra pessoa, por causa da relação, etimologicamente falando, de persona-máscara-pessoa e, consequentemente, com o papel que desempenhamos e que varia conforme as circunstâncias). Como compreender, por exemplo, o sentimentalismo familiar dos chefões da máfia? Como compreender a intimidade entre Truman Capote e os assassinos de uma família no Kansas, entre o final dos anos 50 e início dos 60? Morin prioriza a compreensão desse museu imaginário (Malraux).

O complexo social é o tema de referência do "situacionista" Guy Debord. Não menos incisivo que Morin, Debord lamenta, lamentava e lamentou a espetacularização da sociedade. 0 que ele entendia por isso? o fato de "o espetáculo ser um instrumento para justificar uma sociedade injustificada" (tese 194), o fato de "o espetáculo se apresentar como uma enorme positividade" (tese 12), o fato de "o espetáculo não ser um conjunto de imagens, mas uma relação social entre pessoas, mediada por imagens" (tese 4). Se na pós-modernidade não existiria mais representação, para Debord ela ainda existiria (algo que se coloque no lugar de outro lugar). Na sociedade do espetáculo dele, deixamos de ser protagonistas e nos tornamos atores sociais. Para Debord, a saída é a 
crítica, nem que seja para, por meio de uma tela escura, afirmar: o cinema está morto. Oscilando entre o marxismo e o anarquismo, Debord opina, enfim, que o espetáculo justifica o injustificável e que seria necessário um retorno à autenticidade com a ajuda da crítica (tese 204). Fica a pergunta: é possível vivermos em outro mundo que não este? O que é autenticidade, após vermos com Baudrillard que o real é um hiper-real? Este mundo, na opinião de Gilles Lipovetsky, é individualista, e o indivíduo se apoia na visão de mercado e de eficiência técnica. Se antes a modernidade era limitada, hoje ela é consumada. Vive-se na hipermodernidade. Lipovetsky observa vários graus de modernidade (primeira, de segundo e terceiro tipos e até uma terceira etapa de modernidade). $O$ aporte é linear, porque ele imagina um futurismo moderno em contraposição ao presenteísmo contemporâneo maffesoliano. É contra Maffesoli, aliás, que Lipovetsky situa a crítica do carpe diem, o viver o presente com o máximo de possibilidades que ele oferece, aqui e agora. Para Lipovetsky, não predomina a plenitude do instante, mas um presente "dividido, apreensivo e assombrado pelo vírus e pelos estragos da passagem do tempo" (2006: 74). Lipovetsky denuncia uma moral à la carte. De novo, como em outros pensadores, persiste uma ideia do paradoxo subjacente tanto à filosofia de Lipovetsky quanto à de Maffesoli: o hiper-hoje é o pós-de ontem.

Para Dominique Wolton, o essencial em um sistema de comunicação não é a tecnologia. Nesse ponto, ele é contrário à tese de "eficiência técnica" de Lipovetsky. Se existem muitos teóricos que acreditam haver uma revolução em curso com a criação de uma rede mundial de computadores, esse não é o caso de Wolton. Na opinião dele, é preciso, antes de tudo, analisar o sistema tecnológico, o modelo cultural dominante e o projeto que sustenta a organização econômica. Ele se baseia no tripé técnica, cultura e sociedade. São os laços entre eles, em maior ou em menor grau, que o interessam. Em síntese, o questionamento de Wolton é saber que papel a comunicação ocupa na sociedade. Estamos ou não presenciando uma revolução tecnológica (e, portanto, social) com o advento da Internet? Ela é tão importante quanto o foram a imprensa, o telefone, o rádio e a televisão? Por isso, ele pergunta, em um de seus trabalhos: Internet, e depois?

Wolton, ainda, defende um espaço midiático público de qualidade. Para ele, isso seria possível aumentando a oferta, e um fator importante para promovê-la seria inovando a programação da tevê com criatividade. Televisão, segundo Wolton, é fator de coesão social. Partindo de uma ideia de política no sentido tradicional do termo, e não no sentido transfigurado de Maffesoli, Wolton culpa as elites por não democratizarem a mídia. Nesse sentido, a técnica estaria sendo usada como uma arma política, e não para o enriquecimento cultural. A Internet não viria para substituir a tevê, pois não haveria oposição entre elas, de acordo com Wolton. Somos controlados pelas novas tecnologias? Wolton valoriza o sujeito, e, para isso, a comunicação deve construir valores no sentido de caminhar rumo a uma sociedade melhor. Trata-se de uma utopia na qual Wolton acredita e que espera, como em toda utopia, mesmo que não seja realizada, que ela se concretize.

18 Televisão é um dos temas preferidos do sociólogo francês Pierre Bourdieu. Ele ataca o sistema de produção televisivo, que aliena e produz um discurso que pode não ter qualquer importância para os outros. É a retomada da ideia de manipulação da Escola de Frankfurt. Na televisão, o sistema que funciona é o de punição e recompensa. Podese estender essa tese a outros veículos. A mídia é perversa, denuncia Bourdieu. 0 pensamento dele também é crítico. É preciso denunciar os mecanismos de alienação de 
uma sociedade neoliberal. A mesma sociedade que promoveu, na opinião de Alain Finkielkraut, a derrota do pensamento. Para ele, a barbárie se apoderou da cultura por meio da industrialização do lazer, e "as obras do espírito teriam sido reduzidas a quinquilharias" (Finkielkraut, 1988: 158).

Pessimista, Finkielkraut divide a cultura em superior, média e inferior. Ele não distingue mais a fronteira entre a cultura e o divertimento, se é que houve alguma antes. Se a cultura de massa é irreversível, não seria melhor perguntar: o que fazer com ela? E, nesse caso, existe uma forte dose de subjetividade. Como fica quando um operário se interessa por um filme de Godard e o próprio Godard se interessa por um filme de Spielberg? A divisão entre culturas não é tranquila. $O$ autor de A derrota do pensamento vive no Iluminismo, pois acredita em valores universais. Logo, critica o multiculturalismo. Finkielkraut é um moderno radical contra a pós-modernidade.

Paul Virilio, por sua vez, não é menos catastrofista. Ideólogo da velocidade (dromologia), Virilio acredita que toda invenção traz consigo o dano contrário. Ou seja, o navio naufraga e o avião cai. Portanto, tudo é descartável. Também iluminista, a exemplo de Finkielkraut e de Pierre Lévy em relação ao virtual, Virilio considera o ideal de transparência da comunicação inalcançável. Não é por meio da velocidade, seja ela qual for, que se encontra a solução dos problemas, sejam eles quais forem. 0 pessimismo de Virilio pode ser considerado realista? o que dizer da grande quantidade de pessoas cujo ritmo de vida é o equivalente a 78 rotações por minuto dos antigos elepês? Mesmo o francês, que tem acesso à tecnologia de ponta, utiliza um sistema antigo - para não dizer arcaico - informatizado, o Minitel. Como preencher um simples formulário padrão em papel se não pudermos ou quisermos utilizar a escrita manual? Pelo computador?

21 Até que ponto a sociedade se transforma com a velocidade? A velocidade de um navio na época dos grandes descobrimentos não seria análoga à de um avião na atualidade? 0 incremento da tecnologia digital não tem incentivado a volta de exercícios estéticos com pin-holes? O grande número de filmes de ação não estaria provocando um grande número de comédias românticas? Portanto, a velocidade sempre irá se chocar com o seu contrário ou com a sua neutralização. $O$ imaginário é imprevisível. Como querer que não se "acelere" (e é bom deixar essa palavra entre muitas aspas) a fabricação de artefatos só pelo fato de eles, possivelmente, gerarem uma possível catástrofe? Resultado dessa aceleração é o virtual. Qual é a importância dele? O que isso quer dizer e até que ponto nos afeta?

Pierre Lévy acredita, utopicamente, que estamos a caminho de uma "inteligência coletiva". Virtual é técnica. $O$ martelo ao ser usado como extensão do braço passa a ser virtualizado. Só que a expansão imaginada por Lévy extrapola, e muito, a virtualidade de um simples artefato. Inserido em uma perspectiva iluminista (no sentido de esclarecer as consciências) e progressista (o futuro nos sorri), ele acredita em uma metarrevolução. $O$ virtual, dessa forma, também seria um não-lugar, um território nãopalpável no qual as pessoas seriam cooperativas, e não competitivas. Haveria uma inteligência em rede. Portanto, não seríamos mais autores de nossos atos? Pensaríamos todos da mesma forma? Não há como prever.

Poderíamos, ainda, ver algumas aproximações entre Lévy e a sociologia do imaginário em Maffesoli. Em "No fundo das aparências" (1996), Maffesoli diz que a solidariedade social acontece por uma forte carga estética (p. 15). Quem sabe essa estética não será o traço aglutinador daquilo que Léyy entende por rede? Outra aproximação com Lévy 
poderia ser a noção em Maffesoli de tactilidade contemporânea, no sentido de uma agregação indiferenciada (1996: 35). Ou, ainda, o sentido de religação, que, em Maffesoli, não muito diferente da inteligência coletiva em Lévy, seria a confiança no mundo compartilhado (1996: p. 76). "Novas maneiras de pensar e de conviver estão sendo elaboradas no mundo das telecomunicações e da informática” (Lévy, 1993: p. 7). Estas "novas maneiras" de que fala Lévy são semelhantes ao paradigma pós-moderno, uma vez que, segundo o autor canadense, “[...] as relações entre os homens, o trabalho, a própria inteligência dependem, na verdade, da metamorfose incessante de dispositivos informacionais de todos os tipos" (1993: p. 7). A informática avançada, na constatação de Lévy, seria, para Maffesoli, o que este sociólogo entenderia por "tecnologia de ponta".

Conforme outro ensaísta, a pós-modernidade só pode ser apreendida num cotejamento com a modernidade, e, ainda segundo ele, um traço distintivo entre elas seria o modo como os indivíduos se relacionam com a ideia de tempo (Coelho, 1997: 310). Trata-se, portanto, de uma questão de sensibilidade. Se aplicarmos esse termo à ideia de autoria, teríamos uma sensibilidade autoral. Ao contrário da tese estruturalista, que eliminou o autor que cria a obra segundo "determinantes pessoais" (Coelho, 1997: 63), observa-se na atualidade um retorno da autoria, seja cinematográfica, literária, publicitária ou televisiva. Existe um inchaço de produções autorais, não mais com a preocupação de se fazer uma obra-prima, perfeitamente acabada, mas sim pelo fato de se dar algo de si para o gozo coletivo, o que Maffesoli caracterizou como orgiasmo. Esse é o jogo da pósmodernidade, o de valorizar um modo de ser sensível à complexidade do instante, e, mais significativo de tudo, integrar as contradições próprias de um sentimento antes trágico do que dramático da existência.

Alguns autores que falam da pós-modernidade se referem não diretamente a ela, mas de forma transversal. Neste jogo, porém, estão, conscientemente ou não, falando de uma pós-modernidade. Mas um desses autores se diferencia dos outros em relação ao uso dessa expressão: é Michel Maffesoli. O sociólogo francês assume a condição pósmoderna, e, mais até que Lyotard, faz dessa pós-modernidade o embasamento de sua teoria anárquica ("tudo vale"), sustentando que vivemos um regime mais tribal ("noturno", para usar a expressão de Durand, em contraposição ao "diurno"). Maffesoli é uma espécie de discípulo (ou melhor, filho espiritual) de Durand, que, por sua vez, é discípulo de Bachelard, o filósofo que trata da dinâmica das imagens, o que Durand irá estender para a imaginação dos símbolos (ou imaginação simbólica).

Razões e crenças são ambivalentes. Por isso, a pós-modernidade inclui, também, o arcaísmo e o retorno do mito. Maffesoli diria, até, que a pós-modernidade reside, justamente, nessa união entre elementos arcaicos e tecnologia de ponta. Ou seja, o homem é um animal racional que busca, na natureza, uma explicação para a sua existência, e, por não encontrá-la lá, na sua origem, procura uma resposta simbólica para a vida. E desse simbolismo é feito não só o cinema, uma arte por excelência para a expressão e impressão de um imaginário, mas também este "museu" das manifestações culturais, que servem, nas suas diferentes modulações, para reequilibrar a espécie humana. 


\section{BIBLIOGRAFIA}

BACHELARD, G. (1988), A poética do devaneio, São Paulo, Martins Fontes.

BAUDRILLARD, J. (2002), Tela tota: mito-ironias da era do virtual e da imagem, Porto Alegre, Sulina.

BAUDRILLARD, J. (1991), Simulacros e simulação, Lisboa, Relógio D’Água.

BOURDIEU, P. (1996), Sobre a televisão, Rio de Janeiro, Zahar.

COELHO, T. (1997), Dicionário crítico de política cultural, São Paulo, Iluminuras.

DEBORD, G. (1997), A sociedade do espetáculo, Rio de Janeiro, Contraponto.

DURAND, G. (1997), As estruturas antropológicas do imaginário. Introdução à arquetipologia geral, São Paulo, Martins Fontes.

DURAND, G. (1998), O imaginário. Ensaio acerca das ciências e da filosofia da imagem, Rio de Janeiro, Difel.

DURAND, G. (2000), A imaginação simbólica, Lisboa, Edições 70.

FEYERABEND, P. (1993), Contra o método, Lisboa. Relógio D’Água.

FINKIELKRAUT, Alain (1988), A derrota do pensamento, Rio de Janeiro, Paz e Terra.

LÉVY, P. (1993), As tecnologias da inteligência: O futuro do pensamento na era da informática, Rio de Janeiro, Ed. 34.

LÉVY, P. (1996), o que é o virtual?, São Paulo, Ed. 34.

LIPOVETSKY, G. (2004), Os tempos hipermodernos, São Paulo, Barcarolla.

LYOTARD, J.-F. (1989), A condição pós-moderna, Lisboa, Gradiva.

MAFFESOLI, M. (1996), No fundo das aparências, Petrópoliss, Vozes.

MAFFESOLI, M. (1997), A transfiguração do político, Porto Alegre, Sulina.

MAFFESOLI, M. (2005), o mistério da conjunção, Porto Alegre, Sulina.

MORIN, E. (1989), As estrelas - mito e sedução no cinema, Rio de Janeiro, José Olympio.

MORIN, E. (2005), 0 método 6 - ética, Porto Alegre, Sulina.

SILVA, J. M. (2003), As tecnologias do imaginário, Porto Alegre, Sulina.

VIRILIO, P. (1996), A arte do motor, São Paulo, Estação Liberdade.

WOLTON, D. (2003), Internet, e depois?, Porto Alegre, Sulina.

\section{RESUMOS}

Uma razão sensível permeia o universo imaginário na pós-modernidade. Se na modernidade, que prevaleceu nos dois últimos séculos, vivia-se o drama das soluções possíveis, hoje não: novas categorias estão em jogo, sem que, necessariamente, as anteriores tenham sido eliminadas. Este artigo, pois, pontua essa diversidade de mundivisões por parte de pensadores contemporâneos, considerando o imaginário como a relação entre o fato de estarmos sitiados por determinantes 
materiais e tecnológicas que, nem por isso, nos impedem de sonhar, como no "trajeto antropólogico" em Durand, e esse sonho pode não ser com um futuro glorioso, mas com a fruição do presente, aqui e agora.

A sensible reason permeates the imaginary universe in the post-modernity. If in the modernity, that prevailed in the last two centuries, one lived the drama of the possible solutions, not today: new categories are in game, and the previous ones have not necessarily been eliminated. This article therefore punctuates this diversity of world views by contemporary thinkers, considering the imaginary as the relationship between the fact that we are both depending on mental environment and technology (Durand's "anthropological trajectory"), which do not prevent us from dreaming, and this dream can not be with a glorious future, but with the enjoyment of the present, here and now.

\section{ÍNDICE}

Keywords: Imaginary, post-modernity, technology, sensibility

Palavras-chave: Imaginário, pós-modernidade, tecnologia, sensibilidade

\section{AUTOR \\ EDUARDO PORTANOVA BARROS}

PhD. Pós-doutor pela Sorbonne (Paris V). Bolsista do Programa Nacional de Pós-Doutorado da Coordenação de Aperfeiçoamento de Pessoa de Nível Superior (PNPD/CAPES) junto ao Programa de Pós-Graduação em Ciências Sociais da Universidade do Vale do Rio dos Sinos (Unisinos), Brasil. Tradutor para o português, no Brasil, de Sociologia do imaginário (Editora Sulina, 2007), de Patrick Legros, Frédéric Monneyron, Jean-Bruno Renard e Patrick Tacussel. Pesquisador do Grupo de Pesquisa sobre Imaginário e Comunicação Imaginalis, da Universidade Federal do Rio Grande do Sul (UFRGS), em Porto Alegre (eduardoportanova@hotmail.com) 